\title{
Effect of time on nanoleakage expression in HEMA-free adhesive
}

\author{
Majd T. Qari' ${ }^{1}$, Nouf A. Banakhar ${ }^{1}$, Abdulmalik A. Aljafari' ${ }^{1}$, Omar M. Abuzaina, Ahmed S. Bakry ${ }^{2}$ and Turki A. Bakhsh ${ }^{2 *}$ \\ ${ }^{1}$ Faculty of Dentistry, King Abdulaziz University, P.O. Box 80209, Jeddah 215-89, Saudi Arabia \\ ${ }^{2}$ Faculty of Dentistry, Operative Dentistry Department, King Abdulaziz University, P.O. Box 80209, Jeddah 215-89, Saudi Arabia
}

\begin{abstract}
Objective: To evaluate the effect of increasing time between application of HEMAfree self-etch adhesive and composite on nanoleakage expression.

Materials and methods: Six freshly extracted human sound molars were used. Two-thirds of the roots were removed and the occlusal surfaces were exposed to superficial dentin using low-speed sawing disc. Then, the specimens were bonded with HEMA-free onestep self-etch adhesive (G-Bond; GC, Japan) according to the manufacturer instructions and divided into 2 groups (A and B). Each group contains 3 specimens that were restored with a universal composite (Kalore; GC, Japan). For (A) group: composite restoration was placed and cured within 10 sec following adhesive curing, while in group (B) composite application was carried out after $60 \mathrm{sec}$ delay. Teeth were sectioned into $2 \mathrm{~mm}$ thickness slabs and lined with fast-drying nail varnish. Then, they were immersed in silver-nitrate solution for 24 hrs, rinsed and immersed in photo-developing solution under fluorescent light for 8 hrs. Finally, they were observed under Scanning Electron Microscope (SEM). Results: SEM examination showed no nanoleakage expression in group (A), while heavy silver-nitrate infiltration was observed within the hybrid layer of group (B).

Conclusion: The more we delay composite application after adhesive curing, the higher the chance of nanoleakage to occur.
\end{abstract}

\section{Introduction}

Resin-based composites have been widely used as a restorative material in dentistry for its aesthetic demands. Recently, new developments and formulations of dental adhesives and resin composites have been introduced in order to improve their physical and mechanical properties as well as adhesive-composite adaptation. In spite of that, microleakage and nanoleakage remain the major disadvantages of these resins that may result in absolute restoration failure [1-3].

Nanoleakage was described by Sano et al. [4] as the infiltration of silver-nitrate along the margins of bonding agents under Scanning Electron Microscopy (SEM) or Transmission Electron Microscopy (TEM) [5]. As known, there are numerous types of dental adhesives. Acrylates and especially methacrylates are in widespread use. Most of methacrylatebased adhesives frequently contain 2-hydroxyethyl methacrylate (HEMA). This hydrophilic monomer, HEMA, is essential for preventing phase-separation and maintaining resin monomers in one solution [6]. However, it has been found that HEMA contributes to water sorption and hydrolytic degradation [7-10]. In addition, omission of HEMA has been proven to remove water, separating it from other components upon solvent [5] thus, a higher concentration of solvent is necessary to eliminate HEMA from the adhesive [10]. Accordingly, HEMA-free adhesives might be different in dentine bonding durability from HEMA-rich adhesives [6].

Many studies have been conducted to evaluate nanoleakage expression in HEMA bonding agents. Makishi et al. [7] assessed the micro-shear bond strength and nanoleakage of self-adhesive and selfetching cements [7]. They concluded that self-adhesive resin cement provides better dentin sealing compared to the self-etching primer resin cement with less nanoleakage. Moreover, Hariri et al. [8] performed a quantitative analysis of nanoleakage expression at the adhesive interface and shear bond strength of an etch-and-rinse adhesive system subjected to thermo-cycling and they found that all groups exhibited some degree of nanoleakage [8].

However, Asaka et al. [9] has examined the relationship between the delay of composite application on the adhesives and the bond strength of dentin adhesives. It showed that the placement time of composite to adhesive may be an important factor influencing dentin bond strength of one-step self-etch adhesive systems [9].

Unlike HEMA-free adhesives, many investigations were carried out on HEMA-rich and that would be attributed to the HEMA biocompatibility with many adhesives formulations, in spite of its high allergenic potential [10]. However, most of these studies did not investigate the effect of delayed composite application on nanoleakage expression.

Therefore, the objective of the study was to test the null hypothesis that there is no difference in the nanoleakage expression in the HEMAfree adhesive after delayed composite application at two different interval time.

Correspondence to: Turki A. Bakhsh, Faculty of Dentistry, Operative Dentistry Department, King Abdulaziz University, Jeddah 21381, Saudi Arabia, Tel: $966-$ 12-6401000, Ext: 20326; E-mail: taabakhsh@kau.edu.sa

Key words: adhesive, dentin, HEMA-free, bonding, nanoleakage, tooth, silvernitrate, sem, EDX

Received: December 01, 2016; Accepted: December 22, 2016; Published: December 26, 2016 


\section{Materials and methods}

\section{Tested materials}

Twelve sounds freshly extracted human molar teeth were selected. They were stored in saline solution at $4^{\circ} \mathrm{C}$ before the experiment. A one-step self-etch HEMA-free adhesive (G-Bond; GC, Japan) and a universal resin composite (Kalore; GC, Japan) were used in this study and their chemical compositions are presented in Table 1.

\section{Sample preparation}

After cutting away the root of the selected teeth, the occlusal surfaces of teeth was trimmed until the superficial dentin was exposed using a low-speed sawing disc (IsoMet; Buehler, USA) under water cooling. The occlusal surfaces were then polished with silicon carbide papers under running water (600-grit) to create a standard smear layer. The samples were randomly divided into two groups $(\mathrm{N}=6)$. In $(A)$ group, a light-cured composite restoration was immediately placed and cured within $10 \mathrm{sec}$ following adhesive curing, while in (B) group the composite restoration was placed after $1 \mathrm{~min}$ of delay from the time of adhesive curing. All groups were light cured using LED curing light (1200 mW/ $\mathrm{cm}^{2}$, Elipar S10 LED, 3M ESPE, USA).

\section{Nanoleakage preparation and evaluation}

For nanoleakage assessment, ammoniacal silver-nitrate solution was prepared with a $25 \mathrm{~g}$ of silvernitrate crystals dissolved in $25 \mathrm{~mL}$ of distilled water and $28 \%$ of concentrated Ammonium Hydroxide as reported in the literature [11]. After storage of the specimens in distilled water at $37^{\circ} \mathrm{C}$ for $24 \mathrm{hrs}$, they were embedded in a fast-setting epoxy resin and sectioned occlusogingivally into three slabs with $2 \mathrm{~mm}$ each slab thickness $(n=18)$. Then, each slab was coated with 2 layers of fast-drying nail varnish excluding the resin-dentin interface by 1 $\mathrm{mm}$. After that, they were immersed in silver-nitrate solution for 24 hrs, rinsed under running water and immersed in photo developing solution under fluorescent light for 8 hours. Later, all specimens were lightly polished with diamond pastes/films $(6,3,1 \mu \mathrm{m}$ consecutively), rinsed, sonicated and dried. Then, they were coated with a thin layer of gold sputter and observed under SEM equipped with Energydispersive X-ray spectroscopy (SEM-EDX; JCM-6000 plus Versatile Benchtop, Japan) to examine the nanoleakage within the resin-dentin interface (Figure 1). The EDS detection and quantification of the present elements $\mathrm{Ag}, \mathrm{P}, \mathrm{Ca}$ at the dentin-resin interface were assessed by the EDS graphs software (SEM/EDS; JEOL, Japan).

\section{Results}

Representative SEM-EDX images of the adhesive/dentin interfaces were obtained for both groups. For group (A) specimens, the resindentin interface was smooth with no silver particles within adhesive or hybrid layer as it was confirmed by SEM-EDX (Figure 2A). However, heavy deposition of silver granules was detected in all samples of group (B) at the adhesive-dentin interface as well as within the hybrid layer as it was confirmed by SEM-EDX (Figure 2B).

\section{Discussion}

In adhesive dentistry, the main focus of research is the bonding layer and their interaction with bonded substrates. Adhesive application during restorative procedure is critical and following manufacturer guidelines is essential to obtain proper bonding. However, misusing or unfollowing manufacturer instructions would lead to alteration in the chemistry or the physical properties that would affect adhesivesubstrate interaction. This interfacial disturbance could be identified using silver-nitrate as reported in the literature [11].

Many nanoleakage studies showed the efficacy of TEM and SEM in tracing silver-nitrate particles $[4,12]$. Therefore, SEM combined with EDX was used to assess the interfacial seal at dentin-resin junction.

The current study is evaluating the importance of the time factor upon adhesive curing and followed by composite application. It was found that delaying the application of resin composite beyond $10 \mathrm{sec}$ had significantly affected the interaction between the adhesive and dentin as heavy silver deposition were clearly identified when the composite application was delayed up to $60 \mathrm{sec}$ following adhesive curing.

Most of all-in-one self-etch adhesives contain hydrophilic and hydrophobic monomers that are dissolved in solvent/water. Upon adhesive application and air-drying, the acidic functional monomers will penetrate and partially demineralize the dentin layer. The water contents of the adhesive will extend the conditioned collagen allowing the functional monomers to co-polymerize with the dentin. At the same time, the solvent is supposed to dehydrate the dentin while evaporating $[13,14]$.

The formulation of the utilized adhesive in the study contains acetone blended with water. The acetone acts as a water chaser for the excess of water molecule inside the dentin matrix. After adhesive application, acetone will evaporate rapidly (acetone vapour pressure $30 \mathrm{kPa}$ at $20^{\circ} \mathrm{C}$ ) during air-drying step, while the water contents from the adhesive will requires prolong time to evaporate (water vapour pressure $2.3 \mathrm{kPa}$ at $20^{\circ} \mathrm{C}$ ). This means that there will be some remnants of water within adhesive layer that will act as water channels or water trees, which could induce osmotic water movement through the dentinal tubules and within the hybrid layer. Moreover, allin-one selfetch adhesives act as permeable membrane as reported in the literature. Delaying composite placement over the cured adhesive layer might permit some water permeation over the cured adhesive layer. The current findings are supported by reports in the literature regarding the formation of water trees within the adhesive and the performance of all-in-one self-etch adhesives as permeable membrane $[15,16]$.

Moreover, the variation between group $\mathrm{A}$ and $\mathrm{B}$ also would be attributed to the formation of thick oxygen inhibition layer (OIL) over the adhesive in group B (60 sec delay) that may also contains remnants of solvent and unreacted functional monomer. These remnants of solvent presumed to interfere with polymerization of the subsequently

Table 1. Composition and manufacturer of the composite adhesive system used in this study.

\begin{tabular}{|l|l|l|}
\hline $\begin{array}{l}\text { Material } \\
\text { (Manufacturer) }\end{array}$ & \multicolumn{1}{c|}{$\begin{array}{c}\text { Composition } \\
\text { Number }\end{array}$} \\
\hline $\begin{array}{l}\text { G-Bond } \\
\text { (GC, Japan) } \\
\text { One-step Selfetch Adhesive }\end{array}$ & $\begin{array}{l}\text { 4-MET, phosphoric ester-monomer, UDMA, TEGDMA, } \\
\text { acetone, water, stabilizer, silica filler, water, photo-initiator }\end{array}$ \\
\hline $\begin{array}{l}\text { Kalore } \\
\text { (GC, Japan) }\end{array}$ & UDMA, Fluoroaluminosilicate glass, pre-polymerized filler, silicone dioxide fillers, Photo initiator, pigment \\
\hline
\end{tabular}

Abbreviations: 4-MET, 4-Methacryloxyethyl Trimellitic Acid; UDMA, Urethane Dimethacrylate; TEGDMA, Triethylene Glycol Dimethacrylate. 


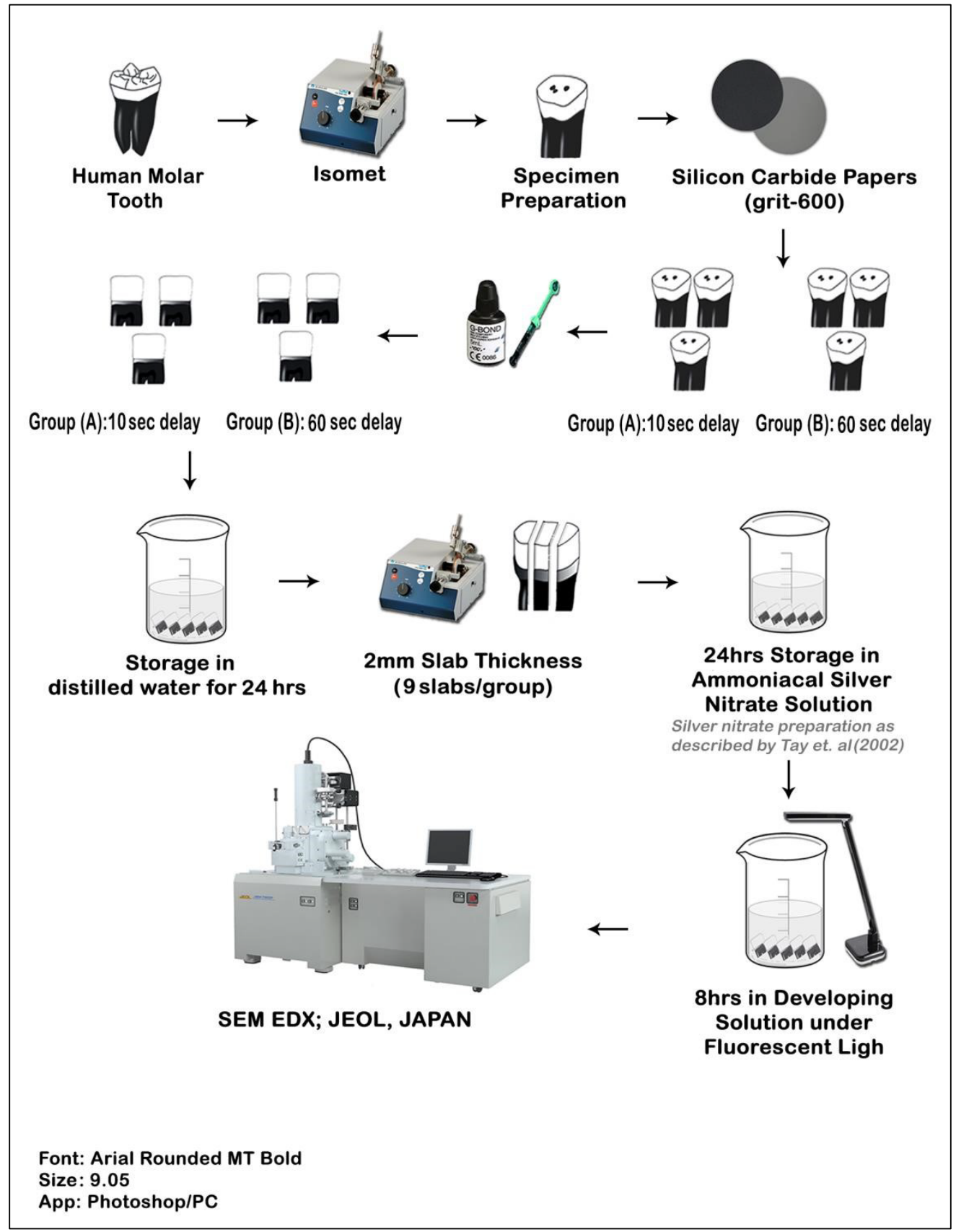

Figure 1. Schematic illustration of sample preparation and examination for nanoleakage investigations using ammoniacal silver-nitrate and SEM-EDX.

applied resin composite and as consequence, this would negatively affect the acid-base reaction between tertiary amines in the composite and the OIL together with the unreacted function monomers on the adhesive $[9,17]$.

By taking into consideration of the above mentioned information, the incomplete removal of the water from the bonding layer as well as the presence of the remnants of solvents/unreacted monomer within the OIL, collectively they will act as suboptimal polymerization reservoirs that would be occupied later by the metallic silver particles as they were perceived in group B (Figure 2B).

Another possibility would be related to the phase separation of this HEMA-free adhesive with the formation of droplets or blisters throughout the adhesive layer that may contribute to the nanoleakage expression upon delayed curing $[18,19]$. The formulation of the G-bond adhesive was significantly affected when the acetone evaporated causing the adhesive monomers to separate from water content [20]. This indeed indicates that the occurrence of droplets is time-dependent as seen in group $\mathrm{B}$.

\section{Conclusion}

Within the limitation of the study, it can be concluded that allin-one HEMA-free G-Bond adhesive is technique sensitive and manufacturer instruction should be followed strictly. Thus, the more we delay composite application after adhesive curing in HEMA-free 

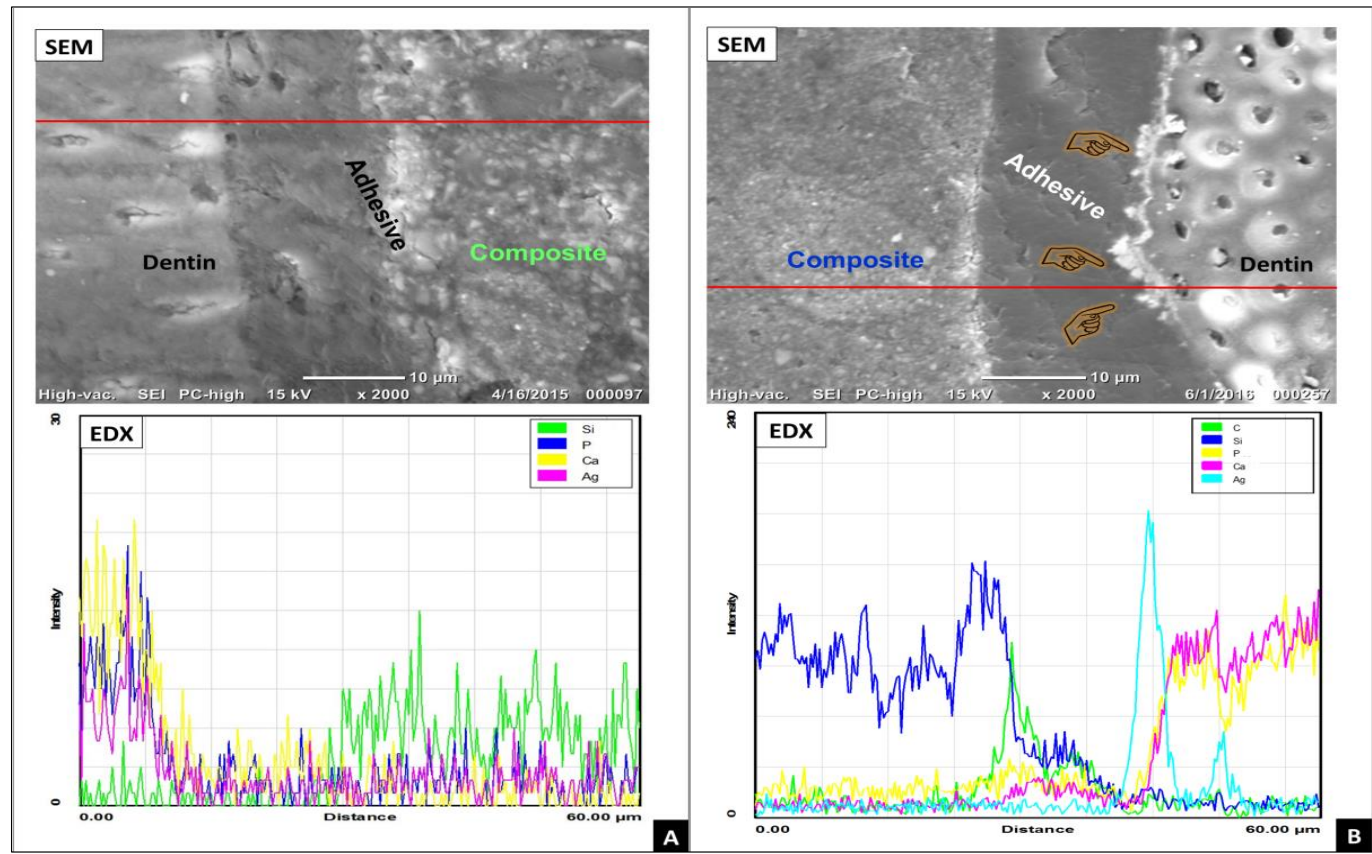

Figure 2. Representative micrographs obtained for groups A and B by SEM-EDX. (A) The obtained SEM image for group A had showed intact hybrid layer without any silver-nitrate penetration at the bonded interface as it was confirmed by EDX. (B) In group B, heavy deposits of silver granules along the adhesive-dentin interface and within the adhesive layer (index finger) were detected by SEMEDX.

adhesive, the higher the chance of nanoleakage to occur.

\section{Conflict of interest declaration}

The authors declare that there is no conflict of interest regarding the publication of this paper.

\section{References}

1. Labella R, Lambrechts P, Van Meerbeek B, Vanherle G (1999) Polymerization shrinkage and elasticity of flowable composites and filled adhesives. Dent Mater 15: 128-137.[Crossref]

2. Bakhsh TA, Sadr A, Shimada Y, Tagami J, Sumi Y (2011) Non-invasive quantification of resin-dentin interfacial gaps using optical coherence tomography: validation against confocal microscopy. Dent Mater 27:915-925.[Crossref]

3. Bakhsh TA, Sadr A, Shimada Y, Mandurah MM, Hariri I, et al. (2013) Concurrent evaluation of composite internal adaptation and bond strength in a class-I cavity. $J$ Dent 41: 60-70.[Crossref]

4. Sano H, Yoshiyama M, Ebisu S, Burrow MF, Takatsu T, et al. (1995) Comparative SEM and TEM observations of nanoleakage within the hybrid layer. Oper Dent 20: 160-167.[Crossref]

5. Van Meerbeek B, Van Landuyt K, De Munck J, Hashimoto M, Peumans M, et al. (2005) Technique-sensitivity of contemporary adhesives. Dent Mater J 24: 1-13.[Crossref]

6. Torkabadi S, Nakajima M, Ikeda M, Foxton RM, Tagami J (2008) Bonding durability of HEMA-free and HEMA-containing one-step adhesives to dentine surrounded by bonded enamel. J Dent 36: 80-86.[Crossref]

7. Makishi P, Shimada Y, Sadr A, Wei S, Ichinose S, et al. (2010) Nanoleakage expression and microshear bond strength in the resin cement/dentin interface. $J$ Adhes Dent 12 393-401.[Crossref]

8. Hariri I, Shimada Y, Sadr A, Ichinose S, Tagami J (2012) The effects of aging on shear bond strength and nanoleakage expression of an etch-and-rinse adhesive on human enamel and dentin. $J$ Adhes Dent 14: 235-243.[Crossref]

9. Asaka Y, Miyazaki M, Takamizawa T, Tsubota K, Moore BK (2006) Influence of delayed placement of composites over cured adhesives on dentin bond strength of single-application self-etch systems. Oper Dent 31: 18-24.[Crossref]

10. Van Landuyt KL, Snauwaert J, Peumans M, De Munck J, Lambrechts P, et al. (2008) The role of HEMA in one-step self-etch adhesives. Dent Mater 24: 1412-1419. [Crossref]
11. Tay FR, Pashley DH, Yoshiyama M (2002) Two modes of nanoleakage expression in single-step adhesives. J Dent Res 81: 472-476.[Crossref]

12. Suppa P, Breschi L, Ruggeri A, Mazzotti G, Prati C, et al. (2005) Nanoleakage within the hybrid layer: a correlative FEISEM/TEM investigation. $J$ Biomed Mater Res $B$ ApplBiomater 73: 7-14.[Crossref]

13. Nikaido T, Weerasinghe DD, Waidyasekera K, Inoue G, Foxton RM, et al. (2009) Assessment of the nanostructure of acid-base resistant zone by the application of allin-one adhesive systems: Super dentin formation. Biomed Mater Eng 19: 163-171. [Crossref]

14. Emamieh S, Sadr A, Ghasemi A, Torabzadeh H, Akhavanzanjani V, et al. (2013) Effects of solvent drying time on mass change of three adhesives. J Conserv Dent 16: 418-422. [Crossref]

15. Malacarne-Zanon J, de Andrade E Silva SM, Wang L, de Goes MF, Martins AL, et al (2010) Permeability of Dental Adhesives - A SEM Assessment. Eur J Dent 4: 429-439. [Crossref]

16. Yiu CK, Pashley EL, Hiraishi N, King NM, Goracci C, et al. (2005) Solvent and water retention in dental adhesive blends after evaporation. Biomaterials26:6863-72. [Crossref]

17. Rueggeberg FA, Margeson DH (1990) The effect of oxygen inhibition on an unfilled filled composite system. J Dent Res 69: 1652-1658.[Crossref]

18. Tay FR, Pashley DH, Suh BI, Carvalho RM, Itthagarun A (2002) Single-step adhesives are permeable membranes. J Dent 30: 371-382.[Crossref]

19. Tay FR, King NM, Suh BI, Pashley DH (2001) Effect of delayed activation of lightcured resin composites on bonding of all-in-one adhesives. $J$ Adhes Dent 3: 207-225. [Crossref]

20. Van Landuyt KL, De Munck J, Snauwaert J, Coutinho E, Poitevin A, et al. (2005) Monomer-solvent phase separation in one-step self-etch adhesives. J Dent Res 84: 183188.[Crossref]

Copyright: (C2016 Qari MT. This is an open-access article distributed under the terms of the Creative Commons Attribution License, which permits unrestricted use, distribution, and reproduction in any medium, provided the original author and source are credited. 